\title{
THE INFLUENCE OF THE RECOVERY CHAMBER PARAMETERS ON THE EFFICIENCY OF BIOMASS GASIFICATION PROCESS
}

\author{
Nataliya Tsyvenkova, Anna Holubenko, Ivan Omarov, Marina Tereshchuk \\ Zhytomyr National Agroecological University, Ukraine \\ nataliyatsyvenkova@gmail.com, anikagogobl@gmail.com,omarov.ivan@gmail.com, \\ marfa3127@yandex.ua
}

\begin{abstract}
The scientific work is devoted to investigation of dependence of length of way that blowing gas streams travels through active zone of gasification chamber, from its design and technological parameters. To find this a tuyere zone form and an analysis of blowing gas streams propagation kinetics through active zone was done. The gasifying chamber design is introduced. The chamber has a distinctive difference: moving tuyeres that can be moved along their axis. To control gasifying process a mathematical dependence was formed that connects average way of blowing gases in gasification chamber with geometrical parameters of this chamber, biomass fuel characteristics and air supply for gasifying. A multifactor experiment is done, where tuyere diameter, tuyere circle diameter and air supply for gasifying are variable factors. Response surfaces are built on that data. Experimental results let us define the optimal diapasons of each parameter that provides the highest gasifier's specific thermal productivity $11.1 \mathrm{MJ} \cdot \mathrm{m}^{-3}$. The obtained measurement results are in high correlation with the calculations. The results let us that it is possible to manage the gasification process and receive high values of gasifier's specific thermal productivity while changing the tuyere circle diameter to match the fuel characteristics of biomass and air supply for gasifying. It is up to 20-23\% higher compared to gasifying biomass such as straw pallets in other known downdraft gasifyer designs.
\end{abstract}

Keywords: downdraft gasifier, gasifying chamber, tuyere, generator gas, specific thermal productivity.

\section{Introduction}

Gasification in downdraft gasifiers is one of the efficient and cheap technologies of thermochemical conversion of the biomass to a combustible gas [1-4]. Although a received gas is characterized by high content of nitrogen and low calorific value $\left(4-6 \mathrm{MJ} \cdot \mathrm{Nm}^{-3}\right)$ [3]

There are a significant amount of works, dedicated to raising the gasification process efficiency in general, as well as raising generator gas' calorific value in partial [1;3-5]. However, by today, there are no ready to use solutions of a downdraft gasifier, capable of high efficiency conversion of a wide variety of fuels into energy. First of all it is explained by serious differences in composition and reaction characteristics of biomass [6-8] and by differences in flow of combustion and gasification processes as well.

There are two ways of raising gasification process efficiency: design changes $[3 ; 9 ; 10]$ and technological methods [11-13]. Particularly design changes could be: improvement of gasification chamber's design, grates' design, bunker's design, etc. [3;9]. Technological methods - using different blowing modes (steam blowing, oxygen saturated air blowing, etc.) [11;13], which is, in turn, coordinated with gasifier's design and biomass fuel characteristics [12]. In works [4;14] methods of raising gasification process effectiveness by providing high temperature modes (up to $1500{ }^{\circ} \mathrm{C}$ ) in active zone [4] and raising reactive surface of the fuel [14].

A wide variety of vegetal raw material and variation in its properties, which are revealed under different operational conditions, and connected with it - uneven distribution of gas streams, as well as desire to describe process adequately gives a lot of mathematical models [13-15]. However, the problem of development of a gas blowing mode, which would be coordinated with gasification chamber's design for a certain class of biofuels, haven't been investigated deeply. Not only the investigations of the length of way, which blowing gases travels through reaction zone, but also an analytical description of tuyere zone based on dynamical characteristics of a separate gas stream are absent. In [2] the need of such investigations is emphasized.

So, to raise the efficiency of gasification process of biomass in downdraft gasifier and receiving combustible gas with high calorific value, a row of investigations with modern science thought and methodology should be done.

The aim of this work is to determine influence of blowing rate, tuyere circle diameter and diameter of tuyere itself on specific thermal productivity of a downdraft gasifier. 


\section{Materials and methods}

The completeness of gasification process is provided under the condition when all oxygen of blowing gases reacts with carbon held in fuel. This, in turn, depends on the length of way that blowing gases travel through fuel layer in gasification chamber. So to find connection between gasification chamber productivity and its geometrical parameters and blowing mode, a kinetics of blowing stream propagation through active zone should be analyzed.

To analyze regularities in evolution of streams in tuyere zone of gasification chamber several guesses were made:

- a flow of blowing gases in streams in tuyere zone is stationary;

- a stream is developing in a tuyere zone, which has a form of a convex cavity that is gradually widening, and is a mixture of air, fuel particles and generated gases;

- maximum stream disclosure radius and length of its axis are determined by geometrical parameters of gasification chamber, and radial cross-section of a stream is round;

- values of temperature, velocity and pressure of a mixture in tuyere zone are equal to mean values in radial cross-section of a stream.

According to reduction theory [16] during gasification in active zone when there is a oxygen, first an oxidation of fuel carbon to $\mathrm{CO}_{2}$ takes place, then - a recovery reaction of $\mathrm{CO}_{2}$ to $\mathrm{CO}$ happens, thus active zone could be divided into two zones: oxidation and recovery zone. According to $[1-3 ; 8 ; 10 ; 15]$ there is no clear boundary between those zones and so this division is nominal. For modelling it was assumed that conversed cone`s generatrix inclination angle is $\alpha_{1}=55^{\circ}$, which makes fuel residues slide freely and evenly down to grates [9]. There is a scheme of kinematic characteristics of a blowing stream in gasification chamber's active zone in Fig. 1.

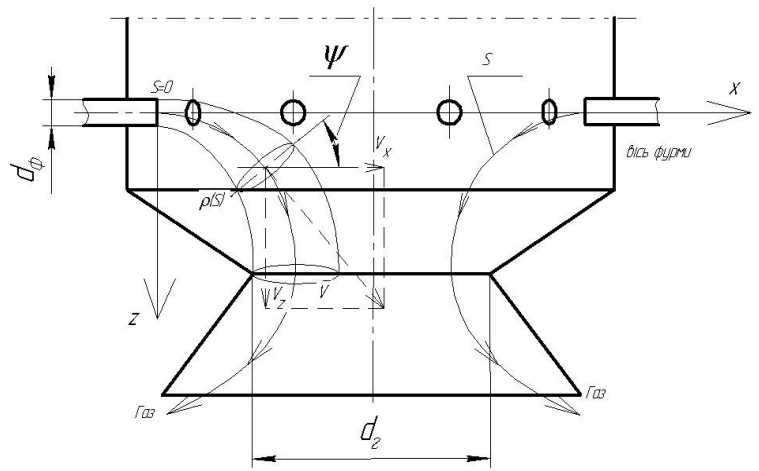

Fig. 1. Blowing gases stream's kinematic characteristics scheme: $V_{x}$-blowing gases' velocity along axis $x$; $V_{z}$ - blowing gases' velocity along axis $z ; V$-resulting velocity vector; $S$ - tuyere zone axis' arc; $d$-diameter of a neck; $d_{t}$ - tuyere diameter; $\rho(S)$ - tuyere zone disclosure radius

Velocities $V_{x}$ and $V_{z}$ could be evaluated from energetic conditions, assuming that $E=$ const for the whole way.

Energy of an elementary volume of the stream with elementary mass is defined as:

$$
\Delta E=\Delta m \cdot V^{2} / 2,
$$

where velocity of an elementary volume of the stream is defined according to Euler method as:

$$
\begin{gathered}
\left\{\begin{array}{l}
V_{x}=f_{1}(x, y, z, t) \\
V_{z}=f_{3}(x, y, z, t)
\end{array},\right. \\
V=V_{x} \cdot \bar{i}+V_{z} \cdot \bar{k},
\end{gathered}
$$

For an established processes, $V=$ const.

According to [17], for an axis symmetrical stream velocity of a main blowing gases stream is defined as:

$$
V_{x}=0.96 \cdot V_{0} \cdot d_{t} /\left[2 \cdot a \cdot S_{x}+0.29 \cdot d_{t}\right]
$$


where $V_{x}$ - is stream velocity in a defined point on distance $x$ from the tuyere`s mouth, $\mathrm{m} \cdot \mathrm{s}^{-1}$;

$d_{t}$ - diameter of a tuyere, $\mathrm{m}$;

$S_{x}$ - distance that was travelled by an elementary volume of a stream from the tuyere's mouth to a defined point on axis $x, \mathrm{~m}$;

$V_{0}$ - initial velocity of stream on the tuyere's mouth, $\mathrm{m} \cdot \mathrm{s}^{-1}$;

$a$ - experimental coefficient, which depends on stream's structure in initial cross-section of the stream (for a stream with round cross-section $a=0.07-0.08$ ) [18].

When decreasing tuyere diameter $d_{t}$ denominator of the formula (4) increases but velocity $V_{x}-$ decreases respectively. So, for the same value of static pressure $h_{0}=$ const, when increasing tuyere's diameter a tuyere's range of reach increases. According to blowing aerodynamics it is better to use fewer tuyeres with bigger diameter. Since there is a tendency for sharp decreasing of blowing gases stream velocity $V_{x}$ along $x$ axis, a boundary value of $V_{x}$, is set at which further propagation af gases along $x$ axis stops. It is obvious that $V_{x}<<V_{0}$, and also $V_{x}<<V_{z}$.

Initial velocity of blowing gases on the tuyere's mouth considering dependencies defined as:

$$
V_{0}=5.06 \cdot N_{2}^{g} \cdot G P /\left(\pi \cdot \alpha \cdot n \cdot d_{t}^{2}\right),
$$

where $\alpha$ - is a coefficient of flow contraction for a tuyere $(\alpha=0.7-1.3)$ [18]; $n$ - quantity of tuyeres; $\mathrm{N}_{2}{ }^{g}$ - nitrogen content in generator gas, $\%\left(N_{2}{ }^{g}=0.38-0.53\right)$; $G P$ - gasifier's productivity by gas, $\mathrm{m}^{3} \cdot \mathrm{h}^{-1}$.

Considering (5) velocity of the main part of blowing gases stream is defined as:

$$
V_{x}=1.54 \cdot N_{2}^{g} \cdot G P /\left[\alpha \cdot n \cdot d_{t} \cdot\left(2 \cdot a \cdot S_{x}+0.29 \cdot d_{t}\right)\right],
$$

Hence length $S_{x}$, which gases travelled along $x$ axis, is:

$$
S_{x}=\frac{\sqrt{5.3 \cdot 10^{-3} \cdot d_{t}^{3} \cdot \alpha \cdot n+0.77 \cdot a \cdot N_{2}^{g} \cdot G P \cdot \tau}}{a^{2} \cdot \alpha \cdot n \cdot d_{t}}-\frac{0.073 \cdot d_{t}}{a},
$$

where $\tau-$ is time that is needed to recover $\mathrm{CO}_{2}$ to $\mathrm{CO}$, h.

Length $S_{x}$ along $x$ axis has boundary values: $\left[0 ; 0.5 \cdot D_{t}-\rho_{\max }\right.$, where $\rho_{\max }-$ is tuyere zone's disclosure radius in neck's plane, $\mathrm{m}$.

To define the length of way along $z$ axis a concept of elementary volume of gasification chamber with elementary height $\Delta h_{i}$ is proposed. Conditions of this modelling are: gas flow in blowing stream is stationary; stream's energy is constant through all way, $E=$ const. Basing on equality of all elementary cross-sections of gasification chamber's height $V_{i}=V_{i+1}=\ldots=V_{n}$ a way travelled by gases along axis $z$, is defined as algebraic sum of heights of elementary volumes:

$$
S_{z}=\sum_{i=1}^{k} \Delta h_{i}=k \cdot \Delta h_{1}+\sum_{m=0}^{k-1}(k-m) \cdot \delta_{m},
$$

where $S_{z}-$ is a way travelled by blowing gases along $z$ axis, m;

$\Delta h_{i}$ - height of elementary volume, m;

$k$ - interval's number;

$\delta_{m}$ - an increment of height of an elementary volume for $m$-th cross-section, $\mathrm{m}$.

Aggregated equation of tuyere zone's axis is described by system of functions:

$$
\left\{\begin{array}{l}
z(S)=S_{z} \\
x(S)=S_{x}
\end{array}\right.
$$

where $S-$ is a tuyere zone's axis arc, $\mathrm{m}$.

Initial conditions defining position of tuyere zone's axis at tuyere's mouth:

$$
\left\{\begin{array}{l}
z(S=0)=0 \\
x(S=0)=0
\end{array}\right.
$$


Tuyere zone's axis is parabola like Fig. 2. Hence a quadratic function could be used to describe its form. Length of tuyere zone's axis is defined as:

$$
d \bar{S}=\sqrt{d z^{2}+d x^{2}}
$$

where $d \bar{S}-$ is real length of axis.

Since $S=f\left(D_{t},\right)$ the Fig. 2 shows the dependence of the length of $S$ (blowing gases stream) from tuyere circle diameter $D_{t}$.

$$
S=0.0017 \cdot D_{t}^{2}-0.85 \cdot D_{t}+114
$$

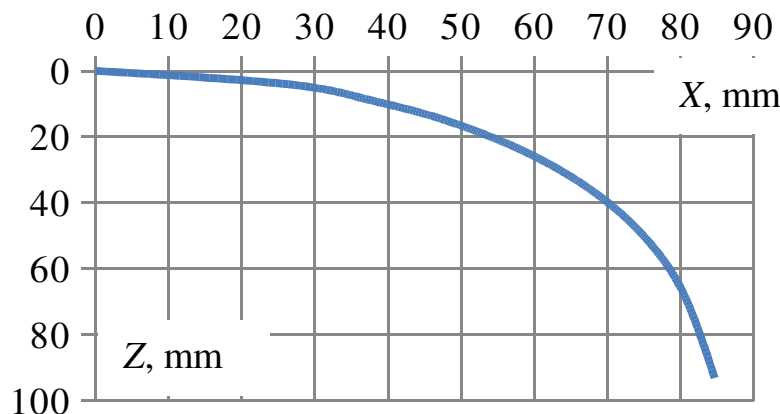

a)

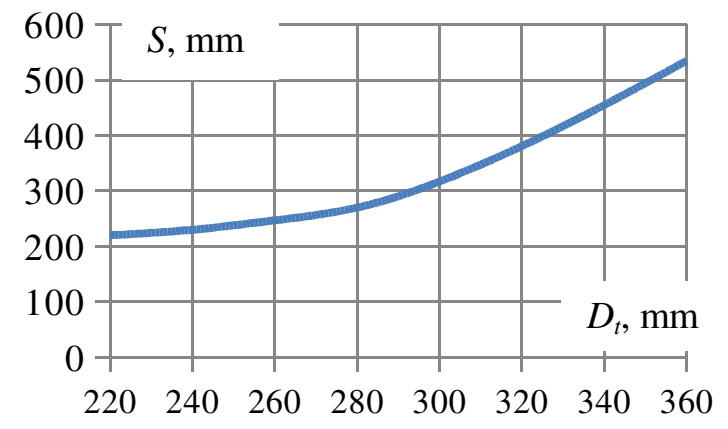

b)

Fig. 2. Blowing gases' way in active zone of gasification chamber $S$ : a - analytic form in coordinates $X-Z ; \mathrm{b}$ - dependence of the length of $S$ from tuyere circle diameter $D_{t}$

Defining $c_{0}$ from boundary conditions $\rho(S=0)=d_{t}$ and $\rho\left(S=S_{\max }\right)=\rho_{\max }$ :

$$
c_{0}=\left(\rho_{\max }-\rho_{\min }\right) / S_{\max }^{2},
$$

where $\rho_{\min }-$ tuyere radius, $\mathrm{m}$;

$\rho_{\max }-$ maximum tuyere zone's disclosure radius in neck's plane, $\mathrm{m}$.

Volume of blowing stream $V_{s t}$ is defined as:

$$
V_{s t}=\pi \int_{0}^{S_{\max }} \rho^{2}(S) d S
$$

where $\rho(S)$ - tuyere zone's disclosure radius, $\mathrm{m}$;

$S$ - length of way travelled by blowing gases through gasification chamber's active zone, $\mathrm{m}$.

An equation which describes tuyere's stream cross-section form contains two unknowns: length of axis $S_{\max }$ and i maximum tuyere zone's disclosure radius $\rho_{\max }$ :

$$
\rho(S)=\rho_{\min }+\left[\left(\rho_{\max }-\rho_{\min }\right) \cdot S^{2}\right] / S_{\max }^{2},
$$

So, considering (15) equation (14) becomes:

$$
V_{s t}=\pi \cdot S_{\max } \cdot\left[d_{t}^{2}+\frac{2}{3} d_{t}\left(\cdot \rho_{\max }-d_{t}\right)+\frac{\left(\rho_{\max }-d_{t}\right)^{2}}{5}\right] .
$$

And gasifier's productivity by gas is:

$$
G P=\frac{\pi \cdot n}{\tau} \cdot\left(k_{t 1} \cdot D_{t}^{2}+k_{t 2} \cdot D_{t}+k_{t 3}\right)\left[d_{t}^{2}+\frac{2}{3} d_{t} \cdot\left(\rho_{\max }-d_{t}\right)+\frac{\left(\rho_{\max }-d_{t}\right)^{2}}{5}\right],
$$

where $k_{t 1}, k_{t 2}, k_{t 3}$-coefficients which depends on gasification chamber's geometry.

For $\alpha_{1}=55^{\circ} k_{t 1}=0.011 \mathrm{~mm}^{-1} ; k_{t 2}=-4.555 ; k_{t 3}=584.4 \mathrm{~mm}$. 
Knowing gases' calorific value and gasifier's productivity by gas a gasifier's thermal productivity could be calculated.

To do experiments a special gasifier was developed. Productivity of a gasifier was $60-68 \mathrm{~m}^{3} \cdot \mathrm{h}^{-1}$ [12]. Experiments were made at atmospheric pressure. A pellets of wheat straw was used as fuel to exclude the influence of fuels moisture content on gasifier's thermal productivity. Pellets meet DIN 5173 and ONorm 7135 standards. Temperature in gasifier's active zone was $900-1100{ }^{\circ} \mathrm{C}$.

To define dependence of influence of air supply, tuyere circle diameter and tuyere diameter on specific thermal productivity of a downdraft gasifier, a multifactor experiment was done. Factor variation intervals are: tuyere diameter $d_{t}-8,10$ and $12 \mathrm{~mm}$; tuyere circle diameter $D_{t}-220,280$ and $340 \mathrm{~mm}$; air supply for gasifying $V_{\text {air }}-45,50$ and $55 \mathrm{~m}^{3} \cdot \mathrm{h}^{-1}$. Tuyere quantity $n$ in gasification chamber equals 10. An investigated parameter was gasifier's thermal productivity $Q_{\text {gas }}$. Factors encoding: $d_{t}=X_{1}, D_{t}=X_{2}, V_{\text {air }}=X_{3}$.

Variation levels of abovementioned factors are given in table 1.

Table 1

Variable factors and limits of their variation for definition of gasifier's thermal productivity

\begin{tabular}{|c|c|c|c|}
\hline $\begin{array}{c}\text { Factor variation } \\
\text { level }\end{array}$ & $\begin{array}{c}\text { Tuyere diameter } \\
\boldsymbol{d}_{\boldsymbol{t}}, \mathbf{m m}\end{array}$ & $\begin{array}{c}\text { Tuyere circle } \\
\text { diameter } \boldsymbol{D}_{\boldsymbol{t}}, \mathbf{m m}\end{array}$ & $\begin{array}{c}\text { Air supply for gasifying } \\
\boldsymbol{V}_{\text {air }}, \mathbf{m}^{\mathbf{3}} \cdot \mathbf{h}^{\mathbf{1}}\end{array}$ \\
\hline Upper level (+) & 12 & 340 & 55 \\
\hline Middle level (0) & 10 & 280 & 50 \\
\hline Lower level (-) & 8 & 220 & 45 \\
\hline
\end{tabular}

To reduce the number of experiments and obtain the regression equation, the mathematical method of the experiment planning based on Box-Behnken quadric plan was used [19].

Planning stage included the following steps: factor encoding, scheduling, randomization tests, implementation plan of the experiment, testing of reproducibility of the experiments, calculation of regression coefficients, assessment of the significance of regression coefficients and adequacy of the test model [19]. For experimental data certainty repetition of experiments under the same conditions equals $k=3$. Eight original experiments were made according to planning matrix and polynomial's linear part coefficients were calculated according to [19]. The values of the model's relative error for all experiments according the plan of multifactor analysis are lower than $3 \%$ [19]. The values of mean relative deviation are lower than $2.04 \%$ [19]. As can be seen the relative error values less than $10 \%$ are considered acceptable in modelling of gasification process [19]. Therefore, it can be concluded that presented model predicts gasification process with a high accuracy.

Gas samples were picked by unpressurised method. Gas composition were analyzed with two channel chromatograph model Agilent 6890 N. Gases' calorific value were calculated basing on its element composition according to GOST 22667-83. Volume of gas GP, produced by gasifier for one hour was measured by flow meter DM.

Specific thermal productivity of downdraft gasifier $Q_{g a s}$ was determined as product of gasifier's productivity by gas $G P$ and calorific value of generator gas.

\section{Results and discussion}

As a result of laboratory experiments and statistical computation a data array of the gasifier's thermal productivity was received, see table 2 .

Experiment results were processed using the software "Statistica". Homogeneity of variances was tested by the Cochrane criterion. Since $G^{\text {com }}=0.22<G^{\text {tabl }}(0.05 ; 15 ; 2)=0.334$ the process is reproduced. When determining of confidence intervals for regression coefficients, the Student test was used, tabulated value of which at a $5 \%$ level of significance and the number of degrees of freedom of experiment variance reproducibility $f_{1}=2$ was $t=4.3$ [19]. The significance of regression coefficients was tested according to the established confidence intervals and covariance. Adequacy test of hypotheses of obtained regression equation was performed by the Fisher criterion.

The estimated value of this criterion in the dispersion of inadequacy $S^{2}$ inadeq $=0.013$ and dispersion $S_{y}{ }^{2}=0.003$ reproducibility of the experiment was: $F^{c o m}=4.39$. 
Tabular value of Fisher's exact test adopted by the $5 \%$ of significance, according to [19], was: $F^{t a b l}\left(0.05 ; f_{1} ; f_{2}\right)=19.38$, where $f_{2}=8$ variance inadequacy degrees of freedom $f_{1}=2$ - variance experiment reproducibility degrees of freedom. Since, $F^{\text {com }}=4.39<F^{t a b l}\left(0.05 ; f_{1} ; f_{2}\right)=19.38$, the hypothesis by the adequacy of the regression equation is confirmed.

Table 2

Planning matrix of a multifactor experiment

\begin{tabular}{|c|c|c|c|c|c|c|c|c|c|c|}
\hline \multirow{2}{*}{ № } & \multicolumn{3}{|c|}{$\begin{array}{c}\text { Values of factor } \\
\text { variables }\end{array}$} & \multicolumn{5}{c|}{ Experiments results } & \multicolumn{3}{c|}{ Model adequacy check } \\
\cline { 2 - 12 } & $X_{1}$ & $X_{2}$ & $X_{3}$ & $Q_{\text {gas } 1}$ & $Q_{\text {gas } 2}$ & $Q_{\text {gas } 3}$ & $Q_{\text {med }}$ & $Q_{\text {med.com }}$ & $\begin{array}{c}\left(Q_{\text {med }}-\right. \\
\left.Q_{\text {med.com }}\right)\end{array}$ & $\begin{array}{c}\left(Q_{\text {med }}-\right. \\
\left.Q_{\text {med.com }}\right)^{2}\end{array}$ \\
\hline 1 & + & + & 0 & 10.43 & 10.34 & 10.53 & 10.43 & 10.52 & -0.09 & 0.007 \\
\hline 2 & + & - & 0 & 10.07 & 10.12 & 10.23 & 10.14 & 10.21 & -0.07 & 0.005 \\
\hline 3 & - & + & 0 & 10.1 & 10.39 & 10.48 & 10.32 & 10.26 & 0.07 & 0.005 \\
\hline 4 & - & - & 0 & 9.73 & 9.87 & 9.82 & 9.81 & 9.72 & 0.09 & 0.007 \\
\hline 5 & 0 & 0 & 0 & 10.99 & 11.07 & 11.12 & 11.06 & 11.09 & -0.03 & 0.001 \\
\hline 6 & + & 0 & + & 10.43 & 10.55 & 10.36 & 10.45 & 10.52 & -0.07 & 0.005 \\
\hline 7 & + & 0 & - & 10.45 & 10.45 & 10.48 & 10.46 & 10.30 & 0.16 & 0.027 \\
\hline 8 & - & 0 & + & 10.24 & 10.22 & 10.21 & 10.22 & 10.14 & 0.08 & 0.007 \\
\hline 9 & - & 0 & - & 9.81 & 9.68 & 9.74 & 9.74 & 9.92 & -0.18 & 0.032 \\
\hline 10 & 0 & 0 & 0 & 10.01 & 11.14 & 11.3 & 11.15 & 11.09 & 0.06 & 0.004 \\
\hline 11 & 0 & + & + & 10.52 & 10.69 & 10.83 & 10.68 & 10.75 & -0.07 & 0.005 \\
\hline 12 & 0 & + & - & 10.49 & 10.61 & 10.38 & 10.49 & 10.53 & -0.04 & 0.001 \\
\hline 13 & 0 & - & + & 10.36 & 10.25 & 10.54 & 10.38 & 10.33 & 0.06 & 0.003 \\
\hline 14 & 0 & - & - & 10.22 & 10.1 & 10.15 & 10.16 & 10.11 & 0.05 & 0.003 \\
\hline 15 & 0 & 0 & 0 & 11.08 & 11.07 & 11.02 & 11.06 & 11.09 & -0.03 & 0.001 \\
\hline Regressionyyyyyyyyyyyyyy \\
\hline
\end{tabular}

Final regression equation of the factors in the specie acquired the form:

$$
\begin{aligned}
& Q_{\text {gas }}=10.98+0.188 \cdot X_{1}+0.211 \cdot X_{2}+0.11 \cdot X_{3}-0.06 X_{1} \cdot X_{2}-0.123 X_{1} X_{3}- \\
& -0.01 X_{2} X_{3}-0.51 \cdot X_{1}^{2}-0.3 \cdot X_{2}^{2}-0.25 \cdot X_{3}^{2}
\end{aligned}
$$

where $Q_{\text {gas }}-$ gasifier's specific thermal productivity $Q_{g a s}, \mathrm{MJ} \cdot \mathrm{m}^{-3}$;

$X_{1}$ - encoded value of tuyere diameter $d_{t}, \mathrm{~mm}$;

$X_{2}$ - encoded value of tuyere circle diameter $D_{t}, \mathrm{~mm}$;

$X_{3}$ - encoded value of the air supply for gasifying $V_{\text {air }}, \mathrm{m}^{3} \cdot \mathrm{h}^{-1}$.

Graphical representations of the abovementioned equation are given on Fig. 3-5. 


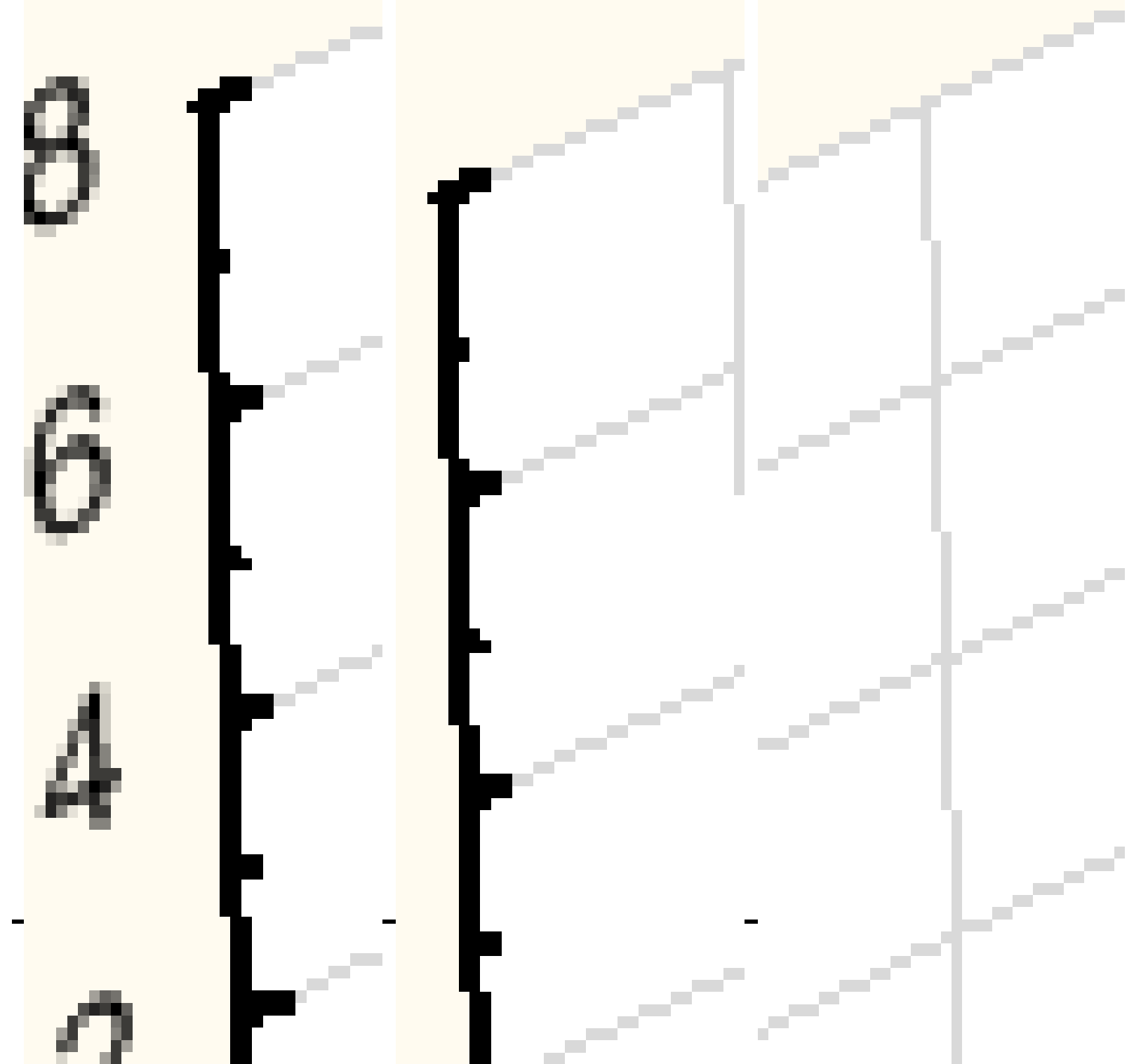


a

b

c

Fig. 3. Dependence of the specific thermal productivity of gasifier $\boldsymbol{Q}_{\text {gas }}$ from tuyere circle diameter $D_{t}$ and tuyere diameter $\boldsymbol{d}_{t}: a-V_{\text {air }}=45 \mathrm{~m}^{3} \cdot \mathrm{h}^{-1} ; b-V_{\text {air }}=50 \mathrm{~m}^{3} \cdot \mathrm{h}^{-1} ; c-V_{\text {air }}=55 \mathrm{~m}^{3} \cdot \mathrm{h}^{-1}$ 


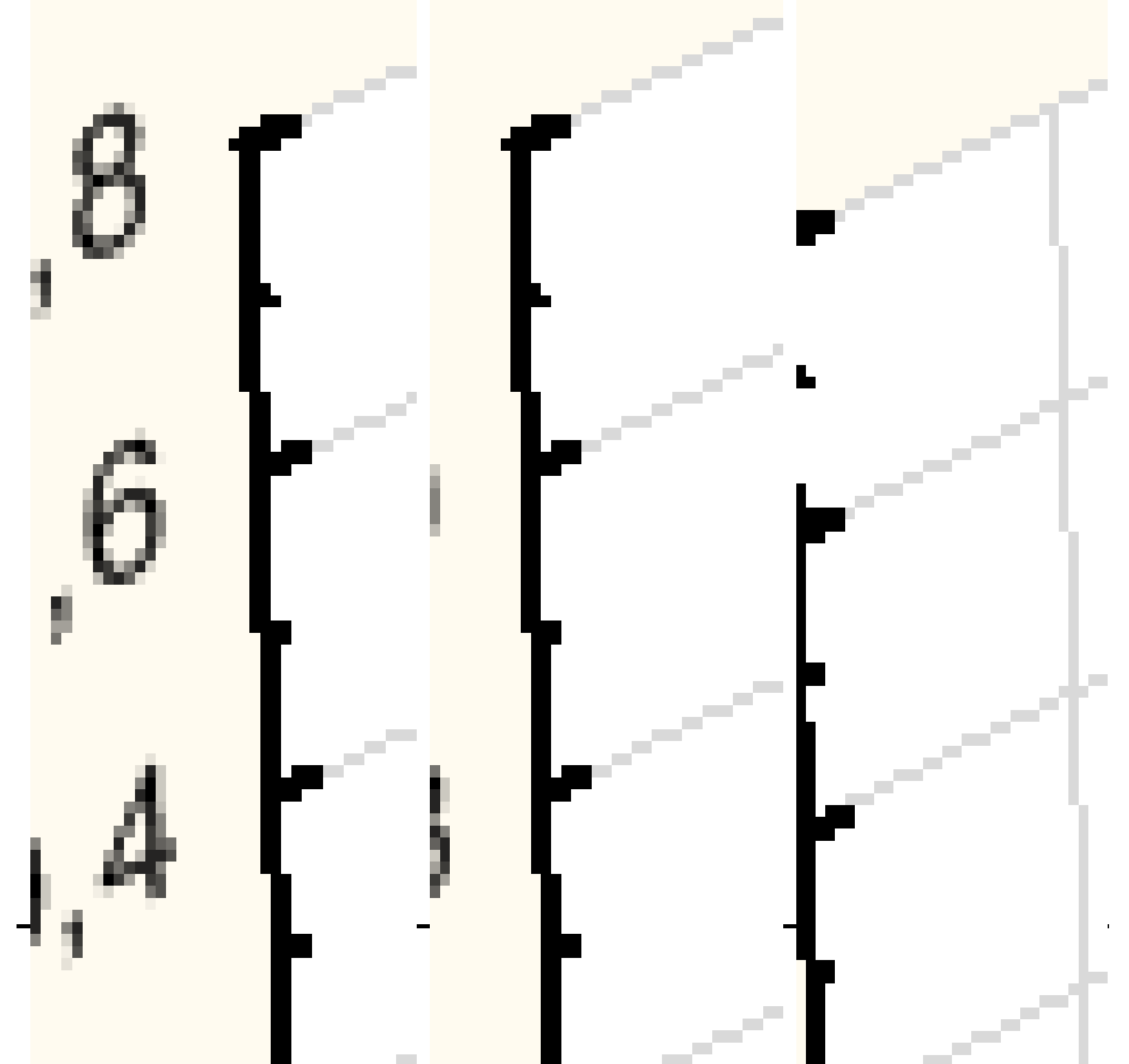




$$
a
$$

b

$c$

Fig. 4. Dependence of the specific thermal productivity of gasifier $Q_{\text {gas }}$ from air supply for gasifying $V_{a i r}$ and tuyere diameter $\boldsymbol{d}_{t}: a-D_{t}=220 \mathrm{~mm} ; b-D_{t}=280 \mathrm{~mm} ; c-D_{t}=340 \mathrm{~mm}$ 


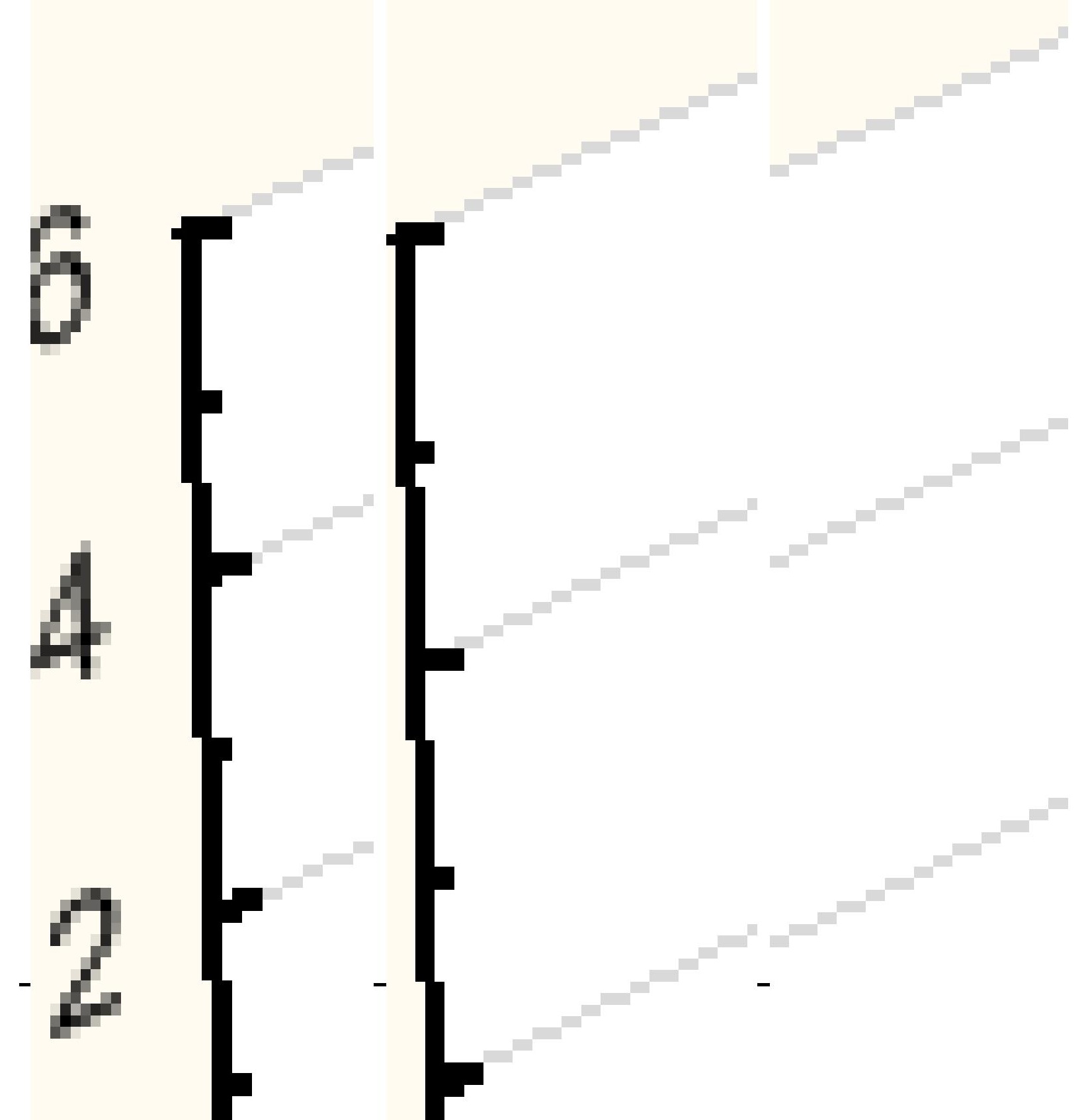


$a$

Fig. 5. Dependence of the specific thermal productivity of gasifier $Q_{\text {gas }}$ from air supply for gasifying $V_{a i r}$ and tuyere circle diameter $\boldsymbol{D}_{t}: a-d_{t}=8 \mathrm{~mm} ; b-d_{t}=10 \mathrm{~mm} ; c-d_{t}=12 \mathrm{~mm}$

From Fig. 3-5 it is seen that increasing all parameters, namely tuyere diameter $d_{t}$, tuyere circle diameter $D_{t}$ and air supply for gasification $V_{\text {air }}$, to a certain extent, promotes increasing the gasifier's specific thermal productivity $Q_{\text {gas }}$. The biggest influence on gasifier's specific thermal productivity $Q_{g a s}$ makes changing tuyere circle diameter $D_{t}$. It is explained by fact that when increasing parameter $D_{t}$ from 220 to 280 the running conditions of aero-dynamical processes in gasification chamber are improving and thus gasifier's thermal productivity grows. The highest values of specific thermal productivity $Q_{g a s}=11.1 \mathrm{MJ} \cdot \mathrm{m}^{-3}$ was achieved for $D_{t}=280 \mathrm{~mm}, d_{t}=10 \mathrm{~mm}$ and $V_{\text {air }}=50 \mathrm{~m}^{3} \cdot \mathrm{h}^{-1}$. However further increasing $D_{t}$ from 300 to 340 мм results in violating stability of gasification process, localization of zones where gasification is held, and decreasing $Q_{g a s}$ as a result. An unburned fuel zone creates in the middle of gasification chamber. Tar content rises in gas from 0.25 to $24 \mathrm{~g} \cdot \mathrm{Nm}^{-3}$, which is unacceptable for further usage in turbines and internal combustion engines. Content of mechanical impurities rises from $0.5-0.8 \mathrm{~g} \cdot \mathrm{Nm}^{-3}$ (for $D_{t}=280 \mathrm{~mm}, d_{t}=10 \mathrm{~mm}$ and $V_{\text {air }}=50 \mathrm{~m}^{3} \cdot \mathrm{h}^{-1}$ ) to $2.3 \mathrm{~g} \cdot \mathrm{Nm}^{-3}$ (for $D_{t}=340 \mathrm{~mm}, d_{t}=10 \mathrm{~mm}, V_{\text {air }}=50 \mathrm{~m}^{3} \cdot \mathrm{h}^{-1}$ ).

A dispersive content of mechanical impurities also was investigated in order to estimate their abrasive properties. It is impossible to separate the dust from tar completely and for that reason particles get glued together hence influencing the error of experiment. So dispersive composition was next: $60 \ldots 70 \mu \mathrm{m}-58 \% ; 45 \ldots 60 \mu \mathrm{m}-11 \% ; 35 \ldots 45 \mu \mathrm{m}-7 \% ; 25 \ldots .35 \mu \mathrm{m}-6 \% ; 15 \ldots 25 \mu \mathrm{m}-$ $4 \% ; 5 \ldots 15 \mu \mathrm{m}-11 \% ; 2.5 \ldots 5 \mu \mathrm{m}-3 \%$. By $89 \%$ of the dust consists of carbon-soot particles. After using the purification system the content of mechanical impurities decreased to $14 \ldots 21 \mathrm{mg} \cdot \mathrm{m}^{-3}$. Permissible level for generator gas used in engines is $20 \ldots 30 \mathrm{mg} \cdot \mathrm{m}^{-3}$ [2]. Another limitation for increasing or decreasing $D_{t}$ is providing a right $D_{t}$ to chamber's neck diameter ratio, which is needed to create conditions for tars cracking. Decreasing tuyere circle diameter $D_{t}$ while $V_{\text {air }}$ and $d_{t}$ are constant, leads to localization of combustion zone in the middle of gasification chamber, and creation of unburned zones near chamber's walls with further decreasing active zone's temperature and thus reduction of $Q_{\text {gas }}$. So changing tuyere circle diameter $D_{t}$ a gasifier's thermal productivity $Q_{\text {gas }}$ could be regulated while other parameters stays unchanged.

When increasing air supply for gasifying $V_{\text {air }}$ from 45 to $50 \mathrm{~m}^{3} \cdot \mathrm{h}^{-1}$ while $D_{t}=280 \mathrm{~mm}, d_{t}=\mathrm{mm}$ the gasifier's specific thermal productivity $Q_{g a s}$ rises from $10.5 \mathrm{MJ} \cdot \mathrm{m}^{-3}$ to $11.1 \mathrm{MJ} \cdot \mathrm{m}^{-3}$, almost by $6 \%$. Similar tendency is traced in all graphs Fig. 3-5. The highest values of specific thermal productivity $Q_{g a s}$ appears in range of air supply for gasifying $V_{a i r}=49-51 \mathrm{~m}^{3} \cdot \mathrm{h}^{-1}$. Right this range was accepted as a rational blowing mode for gasifier operating on straw pellets. Rising gasifier's specific thermal productivity $Q_{g a s}$ is explained by intensifying fuel's carbon oxidation process thanks to oxygen saturation because of more air supplied through tuyere belt into the chamber. Oxidation reaction is endothermic, so a lot of heat produced which is needed for creating $\mathrm{CO}$ - one of the main combustible components of generator gas. Increasing CO content in generator gas increases its calorific value, hence increasing gasifier's thermal productivity in general.

When increasing air supply for gasifying $V_{\text {air }}$ from 51 to $55 \mathrm{~m}^{3} \cdot \mathrm{h}^{-1}$ while $D_{t}=280 \mathrm{~mm}$, $d_{t}=10 \mathrm{~mm}$ the gasifier's specific thermal productivity $Q_{g a s}$ decreases from $11.1 \mathrm{MJ} \cdot \mathrm{m}^{-3}$ to $10.8 \mathrm{MJ} \cdot \mathrm{m}^{-3}$ because excessive air, when goes through fuel layer, is cooling it. Because of fuel carbon taken away with generator gas, equilibrium is shifted to producing more $\mathrm{CO}_{2}$ instead of $\mathrm{CO}$.

Despite the blowing gases' velocity is constant when entering gasification chamber, the drop of this velocity varies gradually along the distance from tuyere. In this case tuyere diameter plays significant role. The less the diameter is the more significant is the drop. Respectively the tuyere "reach" grows with its diameter, while pressure is constant. So, from the point of blowing aerodynamics, it is better to install fewer tuyeres of bigger diameter. An inexpediency of blowing through slots is proved by experiments [2]. In our case with smaller tuyer diameter $d_{t}=8 \mathrm{~mm}$ $\left(D_{t}=280 \mathrm{~mm}\right.$ and $\left.V_{\text {air }}=50 \mathrm{~m}^{3} \cdot \mathrm{h}^{-1}\right)$ a bad penetration of oxygen to the centre of chamber was observed, resulting in poor tar combustion The gasifier's specific thermal productivity was $Q_{\text {gas }}=10.2 \mathrm{MJ} \cdot \mathrm{m}^{-3}$. According to [2] blowing stream velocity on a significant distance from tuyere is back proportional to tuyere`s diameter. When installing tuyeres $10 \mathrm{~mm}$ in diameter an excessive 
pressure in chamber builds up thus resulting in dropping stream's velocity and decreasing the way, which blowing gases travels in gasification chamber. As a result not all oxygen reacts with fuel's carbon and gasification process runs incompletely. Growing excessive pressure in chamber promotes intensive fuel's carbon evacuation, and rising tar and mechanical impurities content in generator gas. The highest values of gasifier's specific thermal productivity $Q_{g a s}=11.1 \mathrm{MJ} \cdot \mathrm{m}^{-3}$ was achieved for $d_{t}=10 \mathrm{~mm}$.

The presented investigations could serve as a base for further research of gasification processes, which took place in downdraft gasifiers when gasifying biomass.

\section{Conclusions}

The experimental study and numerical simulation of gasification process in downdraft gasifier have led to the following conclusions.

1. It is determined that the completeness of gasification process depends on the length of way that blowing gases travel through fuel layer in gasification chamber. A mathematical model, which based on kinematic characteristics of blowing gases, is proposed. It connects the length of way that blowing gases travel in gasification chamber (which depends on geometric parameters of chamber and quantity of air supplied for gasifying) whith gasifier's thermal productivity.

2. With help of multifactor experiment with further data analysis the dependence of specific thermal productivity of downdraft gasifier $Q_{g a s}$ from tuyere diameter $d_{t}$, tuyere circle diameter $D_{t}$ and the air supply for gasifying $V_{\text {air }}$ was investigated. Basing on experimental results we can say that:

- gasifier's thermal productivity rises by 6-10\% while air supply is rising from 45 to $50 \mathrm{~m} 3 \cdot \mathrm{h}^{-1}$. If the air supply is rising further the thermal productivity drops again. Between 49 and $52 \mathrm{~m} 3 \cdot \mathrm{h}^{-1}$ gasifier's thermal productivity is maximized and is between $10.56-11.1 \mathrm{MJ} \cdot \mathrm{m}^{-3}$ for straw pellets;

- while tuyere circle diameter $D_{t}$ rising from 220 to $280 \mathrm{~mm}$ thermal productivity rises by 6$10 \%$ with the fixed tuyere diameter $d_{t}=10 \mathrm{~mm}$ and air supply for gasifying $V_{\text {air }}=50 \mathrm{~m} 3 \cdot \mathrm{h}^{-1}$;

- gasifier`s thermal productivity is maximum and is $Q_{g a s}=11.1 \mathrm{MJ} \cdot \mathrm{m}-3$ while tuyere diameter is $d_{t}=10 \mathrm{~mm}$, air supply for gasifying is $V_{\text {air }}=50 \mathrm{~m} 3 \cdot \mathrm{h}^{-1}$ and tuyere circle diameter is $D_{t}=280 \mathrm{~mm}$.

3. It is possible to manage the gasification process and receive high values of gasifier's specific thermal productivity while changing the variable parameter $D_{t}$ (tuyere can move along its axis during gasifier's operation) to match the fuel characteristics of biomass and air supply for gasifying.

\section{References}

[1] Basu P. Biomass gasification, pyrolysis and torrefaction: practical design and theory. Elsevier, 2013. $548 \mathrm{p}$.

[2] Los L.V. ets. Substantiation of gas producer parameters adapted to vegetable raw material (Обгрунтування параметрів газогенератора адаптованого до рослинної сировини). ZNAEU Courier, vol. 4, No. 2(45), 2014, pp. 206-216. (In Ukrainian).

[3] Susastriawan A.A.P., Saptoad H., Purnomo. Small-scale downdraft gasifiers for biomass gasification: A review. Renewable and Sustainable Energy Reviews, vol. 76, 2017, pp. 989-1003.

[4] Golub G., Kukharets S., Tsyvenkova N. etc. Experimental study into the influence of straw content in fuel on parameters of generator gas. Eastern-European Journal of Enterprise Technologies, vol. 5, No. 8, 2018, pp. 76-86.

[5] Cerone N., Zimbardi Fr., Contuzzi L. ets. Air-steam and oxy-steam gasification of hydrolytic residues from biorefinery. Fuel Processing Technology, vol. 167, 2017, pp. 451-461.

[6] Karps O., Aboltins A., Palabinskis J. Biomass ash utilization opportunities in agriculture. Proceedings of the 8-th International Scientific Conference "Rural development 2017. Bioeconomy challenges", November 23-24, 2017, Aleksandras Stulginskis University, Lithuania, pp. 193-198.

[7] Kakitis A., Nulle I., Ozollapins M. etc. Assessment of combustion parameters of biomass mixtures. Proceedings of International conference " Engineering for rural development 2015", May 20-22, 2015, Jelgava, Latvia, pp. 133-139. 
[8] Barmina I., Valdmanis R., Zake M., etc. Development of gasification/combustion characteristics at thermo-chemical conversion of biomass mixtures. Proceedings of International conference "Engineering for rural development 2017", May 24-26, 2017, Jelgava, Latvia, pp. 54-59.

[9] Tsyvenkova N. M., Golubenko A. A. Pat. No. 80582 UA. Gazogenerator. No. u201212030; declareted: 19.10.2012; published: 10.06.2013, Bul. No. 11.

[10] Sheth P. N., Babu B. V. Experimental studies on producer gas generation from wood waste in a downdraft biomass gasifier. Bioresource Technology, vol. 100, Issue 12, 2009, pp. 3127-3133.

[11] Pauls J.H., Mahinpey N., Mostafavi E. Simulation of air-steam gasification of woody biomass in a bubbling fluidized bed using Aspen Plus: A comprehensive model including pyrolysis, hydrodynamics and tar production. Biomass and Bioenergy, vol. 95, 2016, pp. 157-166.

[12] Kukharets S., Tsyvenkova N., Yarosh Ya. etc. The results of study into the effect of air-steam blast on the low-grade fuel gasification process. Eastern-European Journal of Enterprise Technologies, vol. 6, No. 8(96), 2018, pp. 86-96.

[13] Dejtrakulwong C., Patumsawad S. Four Zones Modeling of the Downdraft Biomass Gasification Process: Effects of Moisture Content and Air to Fuel Ratio. Energy Procedia, vol. 52, 2014, pp. 142-149.

[14]Cuoci A., Faravelli T., Frassoldati A. et. al. Mathematical modeling of gasification and combustion of solid fuels and wastes. Chemical Engineering transactions, vol. 18, 2009.

[15] Pandey S. The Biomass Gasifier: Theory, Practice and Development Guide: The book reflecting the theory of biomass gasifier, practical design and development approach. LAP LAMBERT "Academic Publishing", 2015, ISBN-13: 978-3-659-74935-3.

[16] Knoef H. Handbook: Biomass gasification, 2nd ed. Enschede: Biomass Technology Group, 2012, $500 \mathrm{p}$.

[17]Гусев А.А. Механика жидкости и газа, 3-е изд. (Fluid and gas mechanics, 3 rd ed). Moskow: Yurait Publishing House, 2018, 232 p. (In Russian).

[18]Reed T., Das A. Handbook of Biomass Downdraft Gasifier Engine Systems. Golden: Solar Energy Research Institute, 1988, 140 p. doi: https://doi.org/10.2172/5206099

[19] Мельников С.В., Ацелкин В.Р., Рощин П.М. Планирование эксперимента в исследованиях сельскохозяйственных процессов (An experiment planning in researches of agricultural processes). Leningrad: Kolos, 1980, 168 p. (In Russian). 